\title{
MFG-E8 Regulates Microglial Phagocytosis of Apoptotic Neurons
}

\author{
Abby D. Fuller • Linda J. Van Eldik
}

Received: 21 May 2008 /Accepted: 7 July 2008 /Published online: 1 August 2008

(C) The Author(s) 2008

\begin{abstract}
Phagocytosis is an essential mechanism for clearance of pathogens, dying cells, and other unwanted debris in order to maintain tissue health in the body. Macrophages execute this process in the peripheral immune system but in the brain microglia act as resident macrophages to accomplish this function. In the peripheral immune system, macrophages secrete Milk Fat Globule Factor-E8 (MFG-E8) that recognizes phosphatidylserine "eat me" signals expressed on the surface of apoptotic cells. MFG-E8 then acts as a tether to attach the apoptotic cell to the macrophage and trigger a signaling cascade that stimulates the phagocyte development, allowing the macrophage to engulf the dying cell. When this process becomes disrupted, inflammation and autoimmunity can result. MFG-E8 resides in the brain as well as in the periphery, and microglia express MFG-E8. However, the function of MFG-E8 in the brain has not been elucidated. We measured MFG-E8 production in the BV-2 microglial cell line and the role of this protein in the recognition and engulfment of apoptotic SY5Y neuroblastoma cells. BV-2 cells produced and released MFG-E8, which apoptotic SY5Y cells and the chemokine fractalkine further stimulated. Furthermore, MFG-E8 increased phagocytosis of apoptotic SY5Y cells, and a dominant negative form of MFG-E8 inhibited phagocytosis by BV-2 cells. Finally, brain MFG-E8 levels were altered in a mouse model of Alzheimer's disease. Our data suggest that MFG-E8 acts in
\end{abstract}

A. D. Fuller $\cdot$ L. J. Van Eldik $(\bowtie)$

Department of Cell and Molecular Biology,

Center for Drug Discovery and Chemical Biology,

Northwestern University Feinberg School of Medicine,

303 E Chicago Ave,

Chicago, IL 60611, USA

e-mail: vaneldik@northwestern.edu the brain via microglia to aid in clearance of apoptotic neurons, and we hypothesize that a dysregulation of this process may be involved in neurodegenerative disease.

Keywords MFG-E8 - microglia $\cdot$ phagocytosis $\cdot$ apoptosis . fractalkine $\cdot$ Alzheimer's disease

\section{Introduction}

Apoptotic cells and potentially toxic materials are the result of neurodegenerative diseases and normal aging processes (Mochizuki et al. 1996; Su et al. 1994; Thomas et al. 1995; Zhang et al. 1995). The efficient removal of apoptotic material is of utmost importance for protecting the surrounding tissue from damage due to released proteins from dying cells (Savill and Fadok 2000). Therefore, it is critical that immune cells are capable of recognizing apoptotic cells so that they may be efficiently removed from the tissue. During apoptotic cell death, a redistribution of plasma membrane phospholipids occurs which exposes the normally inward facing phospholipid phosphatidylserine (PS) on the surface of the dying cell. In turn, the PS acts as an "eat me" signal for phagocytes to recognize, triggering a cytoskeletal rearrangement in the phagocyte and the engulfment of the apoptotic cell (Henson et al. 2001). This engulfment not only sequesters potentially harmful cellular products from surrounding tissue, it suppresses proinflammatory cytokines to create an antiinflammatory environment to further protect the tissue (Fadok et al. 1998).

The mechanics of PS-triggered phagocytosis have been studied in some detail in the peripheral immune system, where phagocytes recognize the exposed PS on apoptotic cells either directly through a PS receptor (Fadok et al. 
2000) or through opsonized bridging proteins such as milkfat globule EGF factor-8 (MFG-E8; Hanayama et al. 2002) and Growth Arrest Specific Gene-6 (Chen et al. 1997; Hall et al. 2005). MFG-E8, shown to be released by macrophages, recognizes and binds PS on apoptotic cells, allowing MFG-E8 to then engage an integrin receptor $\left(\alpha_{\mathrm{v}} \beta_{3}\right.$ or $\left.\alpha_{\mathrm{v}} \beta_{5}\right)$ on the macrophage forming a tether between the two cells (Hanayama et al. 2002). This triggers a conformational change in the integrin receptor that signals the recruitment of the CrkII-DOCK180-Rac1 complex and thus the activation of Rac1 (Akakura et al. 2004; Albert et al. 2000). The result is cytoskeletal reorganization in the macrophage and its transformation into a phagocyte capable of removing the apoptotic cell. However, when interference with this tethering occurs, such as insufficient production of MFG-E8, a proinflammatory state is created, evident in $\mathrm{MFG}-\mathrm{E}^{-/-}$mice that show the symptoms of an autoimmune disorder resembling systemic lupus erythematosus (Hanayama et al. 2004).

While a significant amount of work supports this mechanism in the peripheral immune system, no studies have been done to examine a role for MFG-E8 in the process of apoptotic cell phagocytosis in the brain. Microglia, which are similar to macrophages in the periphery of the body, act as the phagocytic cells in the brain to remove harmful material and dying cells (Garden and Moller 2006; Stolzing and Grune 2004; Witting et al. 2000), but little is known about MFG-E8 and microglia function. MFG-E8 is expressed in the brain (Boddaert et al. 2007; Hanayama et al. 2004), and one report indicates fractalkine (CX3CL1) treatment of cultured microglia increases MFG-E8 mRNA levels (Leonardi-Essmann et al. 2005). Fractalkine is a 95$\mathrm{kDa}$ chemokine expressed by neurons throughout the brain in both membrane-bound and soluble forms (Harrison et al. 1998). The membrane-bound protein is cleaved to its soluble form following cell stress or injury, which then acts as a chemoattractant for $\mathrm{T}$ cells, monocytes, and potentially microglia (Bazan et al. 1997). This is supported by the observation that microglia are the only cells in the brain that express CX3CR1, the fractalkine receptor (Harrison et al. 1998). In the periphery, fractalkine stimulates MFG-E8 production by peritoneal macrophages and increases the phagocytosis of apoptotic thymocytes (Miksa et al. 2007). Likewise, studies report abnormal levels of fractalkine in neurodegenerative diseases such as Alzheimer's disease (AD) and AIDS-associated dementia (Erichsen et al. 2003; Kim et al. 2008), therefore suggesting a potential role for MFG-E8 regulation in the progress of these diseases. However, the function of MFG-E8 in the brain is currently unknown.

In the present study, we investigated the hypothesis that MFG-E8 is produced by microglia and regulates the ability of microglia to phagocytose apoptotic neurons. In order to test this potential mechanism, we utilized the BV-2 microglia cell line and the SY5Y human neuroblastoma cell line as a model system for glial-neuronal interactions. We report here that BV-2 production of MFG-E8 can be modulated by the presence of apoptotic SY5Y cells as well as by fractalkine. In addition, we studied the phagocytosis of apoptotic SY5Y cells by BV-2 cells in the presence of MFG-E8 or a dominant negative form of the protein. Finally, we report altered levels of MFG-E8 protein in the brains of $\mathrm{Tg} 2576$ mice, a mouse model of Alzheimer's disease overexpressing $\mathrm{APP}_{(\text {swe) }}$. Our findings indicate a conserved mechanism for MFG-E8-mediated clearance of apoptotic cells in the brain, as well as implications of a possible role for this protein in neurodegenerative diseases like AD.

\section{Materials and methods}

\section{Materials}

Both recombinant mouse fractalkine and recombinant mouse MFG-E8 (R\&D Systems, Minneapolis, MN, USA) were resuspended in sterile phosphate-buffered saline (PBS) at $10 \mu \mathrm{g} / \mathrm{ml}$ and used at the concentrations indicated. Antimouse MFG-E8 antibody (R\&D Systems, Minneapolis, MN, USA) was reconstituted at $0.2 \mathrm{mg} / \mathrm{ml}$ in sterile PBS and used at a final concentration of $0.2 \mu \mathrm{g} / \mathrm{ml}$. Bovine serum albumin (BSA), fraction V (Sigma, St. Louis, MO, USA), was resuspended at $1 \mathrm{mg} / \mathrm{ml}$ in sterile PBS and used at a final concentration of $4 \mu \mathrm{g} / \mathrm{ml}$. The plasmid for the dominant negative form of MFG-E8 (D89E) was a generous gift from Dr. Shigekazu Nagata (Osaka University Medical School, Osaka, Japan), and the Flag-tagged D89E was expressed in human $293 \mathrm{~T}$ cells using FuGene 6 transfection reagent (Roche Diagnostics Co, Indianapolis, IN, USA). The D89E protein secreted into the medium was purified using anti-Flag M2 affinity gel (Sigma) as recommended by the manufacturer.

\section{Cell culture}

BV-2 cells, a murine microglial cell line, were originally derived by Dr. Elisabetta Blasi (Blasi et al. 1990) and cultured as previously described (Petrova et al. 1999). SHSY5Y cells, a human neuroblastoma cell line, were obtained from the American Type Culture Collection (Manassas, KS, USA). Both cell lines were maintained in DMEM/F-12 media containing $10 \%$ fetal bovine serum (HyClone, Logan, UT, USA), $2 \mathrm{mM}$ glutamine, and antibiotics $[100 \mathrm{U} / \mathrm{ml}$ penicillin and $100 \mu \mathrm{g} / \mathrm{ml}$ streptomycin (Invitrogen, Carlsbad, CA, USA)] and incubated at $37^{\circ} \mathrm{C}$ with $5 \%$ carbon dioxide. 
Coculture and cell treatments

For dose curve and time course experiments, cells were trypsinized $(0.25 \%$ trypsin, $0.53 \mathrm{mM}$ ethylenediaminetetraacetic acid (EDTA) for $5 \mathrm{~min}$ at $37^{\circ} \mathrm{C}$ ) and seeded at a density of $2.5 \times 10^{5}$ cells per well (BV-2) or $1 \times 10^{5}$ cells per well (SY5Y) in 12-well tissue culture plates. For coculture experiments, SY5Y cells were cultured for 1 day in advance of the experiment. After $24 \mathrm{~h}, \mathrm{BV}-2$ cells were cultured with serum in the same wells as SY5Y cells so that the cells were able to share the same culture media and engage in direct cell-cell contact. In the case of UV-treated cultures, SY5Y cells were exposed to $50 \mathrm{~J} / \mathrm{m}^{2}$ of UV light for $20 \mathrm{~s}$ with a Stratalinker $1200 \mathrm{UV}$ crosslinker $1 \mathrm{~h}$ prior to coculture. At the indicated time points, conditioned media was collected, centrifuged at $3,000 \times g$ for $3 \mathrm{~min}$ at $4^{\circ} \mathrm{C}$, and supernatants were collected. Cells were washed one time with PBS then $100 \mu \mathrm{l}$ of lysis buffer $(20 \mathrm{mM}$ Tris $\mathrm{pH}=8$, $2 \mathrm{mM}$ EDTA, $0.5 \%$ Triton X-100, $1 \mathrm{mM}$ phenylmethanesulfonylfluoride, $1 \mu \mathrm{g} / \mathrm{ml}$ leupeptin, $2 \mathrm{mM}$ sodium orthovanadate) was added. Cell lysates were sonicated for $8 \mathrm{~s}$ on ice, centrifuged at $10,000 \times g$ for $10 \mathrm{~min}$ at $4^{\circ} \mathrm{C}$, and supernatants were analyzed by Western blotting.

\section{Cell viability assays}

The combination of two cell viability assays allowed the determination of a point when cells were dying but still maintained membrane integrity. The number of viable cells with and without UV radiation was determined using the CellTiter 96 AQueous One Solution Cell Proliferation Assay (Promega, Madison, WI, USA). This assay, known as the MTS assay, utilizes the chemical reduction of a tetrazolium substrate by the NADPH or NADH present in living cells. Therefore, a higher number of living cells in a sample results in more formation of a color product at $490 \mathrm{~nm}$. The assay was performed according to manufacturer instructions. To assess the effect of UV radiation on the membrane integrity of SY5Y cells, a lactate dehydrogenase (LDH) assay was performed on the conditioned media from control and UV-exposed cells according to manufacturer instructions (Sigma). The assay measures released LDH by its ability to convert NAD to NADH, which in turn reacts with a tetrazolium dye substrate. The optical densities (OD) of the colored product were measured at $490 \mathrm{~nm}$.

\section{Western blotting}

Western blotting was carried out as previously described (Petrova et al. 1999). Briefly, cell lysates (1:2) and media (1:3) were prepared in sodium dodecyl sulfate (SDS) containing sample buffer, and equal volumes of both cell lysates and media were separated by 10-14.5\% SDSpolyacrylamide gel electrophoresis (SDS-PAGE; Bio-Rad, Hercules, CA, USA). Proteins were transferred to Immobilon-P membranes (Millipore, Billerica, MA, USA), and membranes were probed with rabbit polyclonal antimouse MFG-E8 primary antibody $(0.2 \mu \mathrm{g} / \mathrm{ml}, \mathrm{R} \& \mathrm{D}$ Systems $)$ or mouse monoclonal anti- $\beta$-actin (1:50,000 dilution, Sigma) overnight at $4^{\circ} \mathrm{C}$. Membranes were then probed with goat antirabbit $(1: 5,000)$ or goat antimouse $(1: 2,000)$ horseradishperoxidase-conjugated secondary antibody (Jackson ImmunoResearch Laboratories, West Grove, PA, USA). Protein bands were detected using SuperSignal West Pico Chemiluminescent Substrate (Pierce, Rockford, IL, USA). Images of blots were acquired for quantification using Kodak 440 digital imager and analyzed with Kodak Molecular Imaging software (Kodak, New Haven, CT, USA).

\section{Phagocytosis assay}

Phagocytosis by BV-2 cells was assayed using the pHrodo Escherichia coli BioParticles Conjugate assay (Molecular Probes, Eugene, OR, USA) according to manufacturer instructions. Briefly, BV-2 cells were seeded at $5 \times 10^{5}$ cells per well in black 96-well tissue culture plates for $24 \mathrm{~h}$ prior to the assay. To prep BioParticles, $2.5 \mathrm{ml}$ of Hank's buffered saline solution with an additional $20 \mathrm{mM} 4-(2-$ hydroxyethyl)-1-piperazineethanesulfonic acid (Invitrogen, Carlsbad, CA, USA) at a pH of 6.8 was used for reconstitution. BioParticles were sonicated in a bath sonicator at $30 \%$ intensity three times for $20 \mathrm{~s}$ each. BioParticles were examined by light microscopy on a hemocytometer to ensure dispersion. Recombinant mouse MFG-E8 (100 ng/ml), D89E (4 $\mu \mathrm{g} / \mathrm{ml})$, or BSA (negative control, $4 \mu \mathrm{g} / \mathrm{ml}$ ) was added to BioParticles and vortexed. Media was then removed from the cells and BioParticles were added along with treatments. Each condition was composed of five replicates. A negative control of wells containing no cells was used to calculate background fluorescence and was subtracted from other wells. The positive control was BV-2 cells treated with BioParticles alone. Plates were read on a SpectraMax fluorescent plate reader, excitation $550 \mathrm{~nm}$ and emission $600 \mathrm{~nm}$. Data shown are representative of four separate experiments.

\section{Imaging}

SY5Y cells were subcultured for 3 days until cells were approximately $70-80 \%$ confluent. Media was then replaced with fresh complete media containing $7.5 \mu \mathrm{M}$ CellTracker Green 5-chloromethylfluorescein diacetate (Molecular Probes) made from a 10-mM dimethyl sulfoxide (DMSO) stock. After $30 \mathrm{~min}$ of incubation at $37^{\circ} \mathrm{C}$ and $5 \% \mathrm{CO}_{2}$, media was exchanged for normal media for an additional 
$30 \mathrm{~min}$. SY5Y cells were then plated in eight-well chamber slides (BD Transduction Labs) at a density of $5 \times 10^{4}$ cells per milliliter and allowed to incubate for $24 \mathrm{~h}$. Six hours prior to coculture, SY5Y cells were exposed to $50 \mathrm{~J} / \mathrm{m}^{2}$ of UV light for $20 \mathrm{~s}$ as described above when indicated and returned to incubation. One hour prior to coculture, media on $70-80 \%$ confluent BV-2 cells was replaced with fresh complete media containing $4 \mu \mathrm{M}$ CellTracker Red CMTPX (Molecular Probes) made from a $10 \mathrm{mM}$ DMSO stock for $30 \mathrm{~min}$ followed by normal fresh media for another $30 \mathrm{~min}$. BV-2 cells were then seeded on top of SY5Y cells at a density of $2.5 \times 10^{4}$ cells per milliliter and treated with MFG-E8 or D89E where indicated. After $2 \mathrm{~h}$, cells were washed one time with sterile PBS, fixed using $4 \%$ paraformaldehyde, washed once more with sterile PBS, and mounted with Vectashield mounting medium containing 4',6-diamidino-2-phenylindole (DAPI; Vector Laboratories, Burlingame, CA, USA).

To analyze the amount of phagocytosis that occurred in this coculture, four images per condition were randomly captured and then analyzed in Metamorph to determine the percent colocalization of red and green labels. This was repeated three times and data were pooled.

\section{Mouse brain tissue preparation}

Hemibrain homogenates from Tg2576 mice (Hsiao et al. 1996) and age-matched wild-type littermates were a generous gift from Dr. Robert Vassar (Northwestern University, Chicago, IL, USA), and samples were prepped as previously described (Oakley et al. 2006). Briefly, hemibrains were homogenized in four volumes of PBS containing protease inhibitor cocktail (Calbiochem, La Jolla, CA, USA). Protein concentrations were determined using a BCA kit (Pierce), and 10-20 $\mu \mathrm{g}$ of protein analyzed by Western blot as outlined above.

\section{Statistical analysis}

Data were analyzed using a two-tailed Student's $t$ test for paired data or using one-way analysis of variance followed by Tukey's post hoc tests of multiple comparisons to determine significant differences between groups. Statistical significance was established when $P<0.05$.

\section{Results}

A microglial cell line produces MFG-E8 that is stimulated by apoptotic neurons and fractalkine

We hypothesize that microglia produce and release MFGE8 which aids in the clearance of apoptotic cells in the brain by enabling the recognition and engagement of microglia with dying cells, a similar mechanism to that observed in the peripheral immune system (Hanayama et al. 2002). Furthermore, we suspect that apoptotic cells stimulate an increase in MFG-E8 so that efficient recognition and clearance of the dying cells is enabled. In order to test this idea, we utilized a coculture system comprised of the murine BV-2 microglial cell line and the human SY5Y neuroblastoma cell line to simulate the glial-neuronal environment, and we then measured MFG-E8 released from BV-2 cells when cocultured with either healthy or dying SY5Y cells. To induce apoptosis in SY5Y cells, SY5Y cultures were exposed to UV light prior to coculture. Therefore, we first verified that exposure of SY5Y cells to $20 \mathrm{~s}$ of UV light induced cell death as determined by the MTS and LDH assays (Fig. 1a,b). In the MTS assay (Fig. 1a), media containing Triton X-100 added to SY5Y cells served as a positive control, which yielded similar levels of MTS production as a negative control containing no cells. MTS production measured at $0,3,6,9$, and $12 \mathrm{~h}$ after the 20-s UV treatment showed a reduction in MTS as soon as $3 \mathrm{~h}$, leveling off at 9-12 h. LDH release measured at the same time points indicated membrane disruption beginning at $3 \mathrm{~h}$ (Fig. 1b). To establish the coculture, we plated SY5Y cells for $24 \mathrm{~h}$ prior to coculture and exposed cells to $20 \mathrm{~s}$ of UV light $1 \mathrm{~h}$ prior to coculture for 12 or $24 \mathrm{~h}$. Apoptotic SY5Y cells stimulated an increased level of MFG-E8 production at both 12 - and 24-h time points (Fig. 1c), indicating that apoptotic cells elicit a robust upregulation in MFG-E8 production and release from a microglial cell line. Interestingly, MFG-E8 levels increased in the control samples from 12 to $24 \mathrm{~h}$ (Fig. 1c) as well as at $48 \mathrm{~h}$ in culture (data not shown). This indicates an endogenous production of MFG-E8 in these cells that accumulates over time. While the exact mechanism of this finding is unknown, the effect may be a function of increased cell density in the culture system, as the MFGE8 protein levels were normalized to $\beta$-actin. Alternatively, cell death due to extended time in culture along with increased cell density could be inducing a rise in MFG-E8 production that is further stimulated by the addition of apoptotic SY5Y cells. A Western blot of the individual cells types insured all MFG-E8 detected in these assays came from BV-2 cells and not SY5Y cells. In both media and lysate fractions, we detected MFG-E8 only in BV-2 cells (Fig 1d).

Because fractalkine is likely released in response to cellular stress and apoptosis (Harrison et al. 1998), we hypothesized that this chemokine may be responsible for some, if not all, of the increase in MFG-E8 production by BV-2 cells in coculture with apoptotic SY5Y cells. In addition, a recent study published by Miksa and colleagues indicates that fractalkine is capable of increasing MFG-E8 


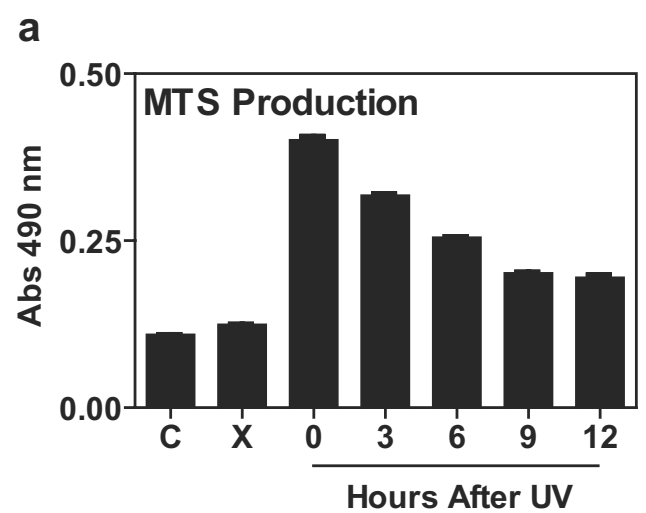

C

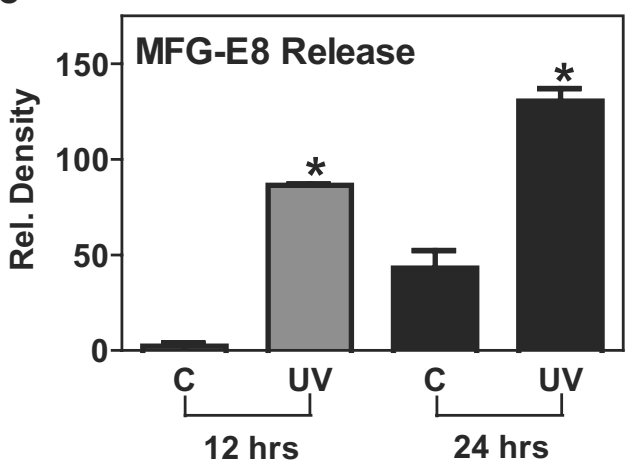

Fig. 1 Apoptotic neurons induce an increase in MFG-E8 release by microglia. SY5Y cells were exposed to UV light for $20 \mathrm{~s}$ to induce apoptosis, and the MTS assay (a) and LDH assay (b) were run to confirm UV-induced cell death. Wells with no cells were used as a negative control (c), Triton-X-100-treated cells were used as a positive control $(X)$. Results were measured at $0,3,6,9$, and $12 \mathrm{~h}$ after UV exposure. For coculture experiments (c), SY5Y cells were exposed to $20 \mathrm{~s}$ of UV $1 \mathrm{~h}$ prior to coculturing with BV-2 microglial cells. Media

\section{b}

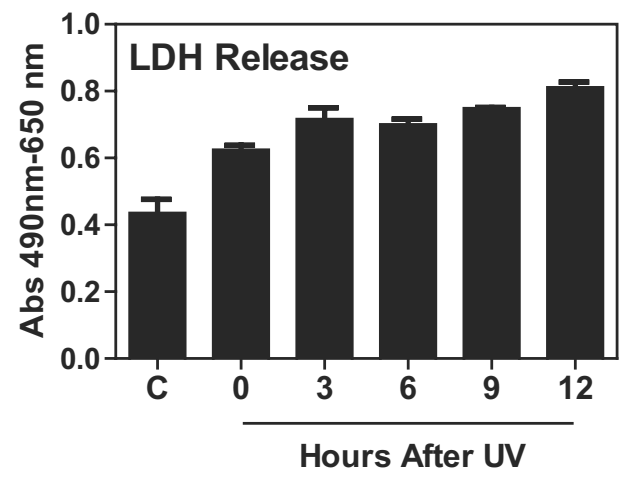

d



was collected from cultures 12 or $24 \mathrm{~h}$ after coculture and analyzed for MFG-E8 by Western blot. Westerns were quantified by densitometry and normalized to $\beta$-actin $(C)$. A representative Western blot is shown in d, demonstrating that MFG-E8 is detected only in BV-2 cells. The data are mean \pm SEM of quadruplicate determinations and are representative of three independent experiments. Significant difference is from vehicle control, ${ }^{*} p<0.05$ expression in primary rat peritoneal macrophages, and these cells also exhibit prophagocytic behavior following treatment with fractalkine (Miksa et al. 2007). This finding combined with a previous report (Leonardi-Essmann et al. 2005) that MFG-E8 mRNA levels increased in microglial cells following treatment with the chemokine fractalkine led us to investigate whether the fractalkine stimulation of BV-2 cells could be involved in the increase in MFG-E8 levels seen in the coculture experiments above. To test this, levels of MFG-E8 protein in BV-2 cell lysates and conditioned media were measured following treatment with $100 \mathrm{ng} / \mathrm{ml}$ fractalkine. As shown in Fig. 2, Western blots confirmed that fractalkine treatment for 24 and $48 \mathrm{~h}$ stimulated MFG-E8 production and release above control levels (Fig. 2a-c). The level of induction above control seen at $48 \mathrm{~h}$ is not as robust as that seen at $24 \mathrm{~h}$, suggesting that a maximal level of stimulation is reached before $48 \mathrm{~h}$ following a single dose of recombinant fractalkine.
MFG-E8 increases phagocytosis by a microglial cell line

After we confirmed MFG-E8 production by a microglial cell line and regulation by both fractalkine and coculture with an apoptotic neuronal cell line, we next investigated the ability of MFG-E8 to increase the phagocytic capacity of microglia (Fig. 3). We hypothesized that adding recombinant MFG-E8 to a phagocytosis assay would result in more connections formed between BV-2 cells and the material intended to be phagocytosed, thereby enabling the engulfment of more particles. To first address this question, we employed the pHrodo assay from Molecular Probes, which measures the uptake of BioParticles, dead E. coli particles tagged with a $\mathrm{pH}$-sensitive dye which fluoresces once it enters the intracellular environment. BV-2 cells were untreated (positive control) or treated with $100 \mathrm{ng} / \mathrm{ml}$ recombinant mouse MFG-E8, $4 \mu \mathrm{g} / \mathrm{ml}$ dominant negative MFG-E8 (D89E), or $4 \mu \mathrm{g} / \mathrm{ml}$ BSA as an unrelated protein 
a

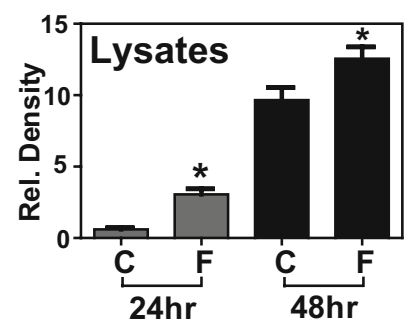

b

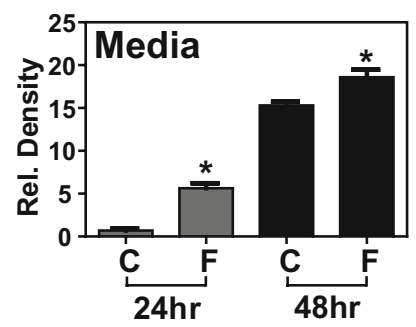

C

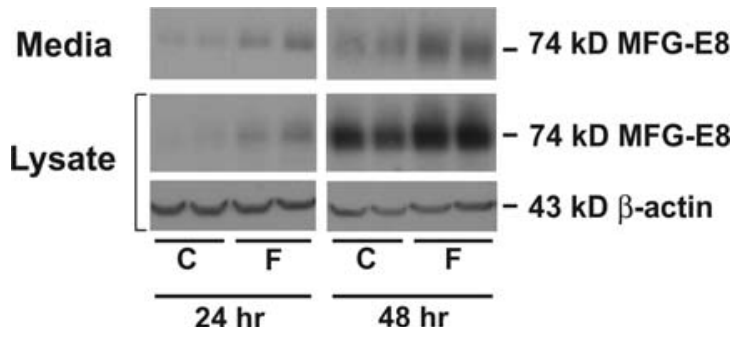

Fig. 2 MFG-E8 is production by microglia is upregulated by fractalkine. BV-2 microglia cells were treated with vehicle $(C)$ or $100 \mathrm{ng} / \mathrm{ml}$ fractalkine $(F)$ for 24 or $48 \mathrm{~h}$ before lysates (a) and conditioned media (b) were collected and analyzed for the presence of MFG-E8 by Western blot (c). Western blots were quantified by densitometry and normalized to $\beta$-actin. The data are mean \pm SEM of quadruplicate determinations and are representative of three independent experiments. Significant difference is from vehicle control, $* p<0.05$

control. MFG-E8 is composed of two epidermal growth factor (EGF) domains E1 and E2, a proline-threonine (PT)rich domain, and two factor-VIII-homologous domains (C1 and C2; Fig. 3a). When MFG-E8 binds PS on the surface of apoptotic cells, the protein then can interact with integrin receptors on macrophages. Therefore, a point mutation in the RGD motif of one EGF domain resulting in a dominant negative form of MFG-E8, called D89E, does not bind to PS (Hanayama et al. 2002) and effectively blocks the function of the protein. D89E expressed in HEK293T cells and purified from the conditioned media reacted with an antibody to MFG-E8 and ran at the correct molecular weight (Fig. 3b). Furthermore, D89E protein samples were confirmed to be relatively pure by visualization on a silverstained SDS-PAGE gel, as indicated by a single visible band (data not shown). The addition of MFG-E8 to the pHrodo assay resulted in a $27.3 \pm 6.8 \%$ increase in phagocytosis (Fig. 3c). Conversely, the addition of D89E suppressed phagocytosis in this assay by $65.8 \pm 18.4 \%$. A higher concentration of D89E $(4 \mu \mathrm{g} / \mathrm{ml})$ as compared to recombinant MFG-E8 $(100 \mathrm{ng} / \mathrm{ml})$ was needed in order to see an inhibition in phagocytosis, possibly due to the ability of the endogenous MFG-E8 to potentially bind multiple PS residues and thus tether multiple apoptotic cells or BioParticles in this experiment. Therefore, an excess of the dominant negative form of MFG-E8 was necessary to flood the PS targets and block phagocytosis. To control for the possibility that adding a protein at $4 \mu \mathrm{g} / \mathrm{ml}$ nonspecifically inhibited phagocytosis, BSA added at an equivalent concentration showed no significant decrease in BioParticle engulfment.

Given that BV-2 cells showed phagocytic activity in the pHrodo assay and that this activity increased in the presence of MFG-E8 and decreased with D89E, we next investigated the potential for BV-2 cells to engulf dying neurons and the effect of MFG-E8 in this system (Fig. 4). SY5Y cells and BV-2 cells were labeled by CellTracker Green and CellTracker Red dyes as described in "Materials and methods." SY5Y cells cultured for $24 \mathrm{~h}$ prior to a 20 -s UV exposure and then cocultured with BV-2 cells for $6 \mathrm{~h}$ after UV exposure were treated with MFG-E8 or D89E for $1 \mathrm{~h}$ and then cells were analyzed by fluorescent microscopy. Colocalization of red BV-2 cells and green SY5Y cells indicated phagocytosis. We observed very little phagocytosis under control conditions where SY5Y cells were not undergoing apoptosis (data not shown). However, phagocytosis increased with apoptotic SY5Y cells (Fig. 4a), and treatment with $100 \mathrm{ng} / \mathrm{ml} \mathrm{MFG-E8} \mathrm{further} \mathrm{enabled} \mathrm{the}$

a

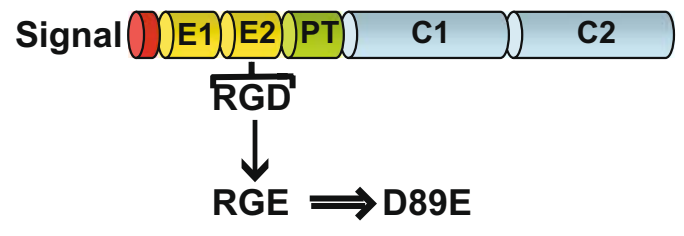

b

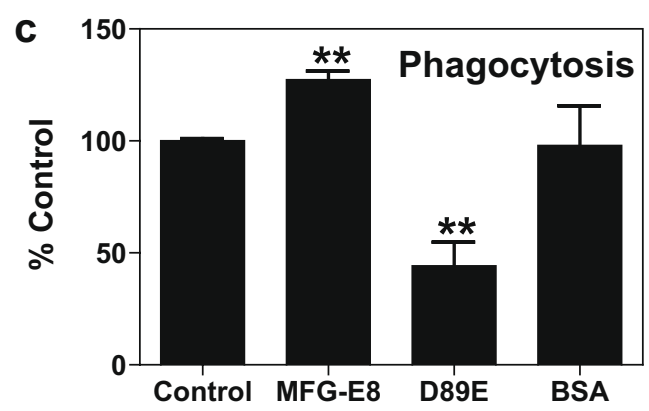

Fig. 3 MFG-E8 increases and dominant negative MFG-E8 (D89E) decreases phagocytosis of BioParticles by microglia. The D89E dominant negative MFG-E8 is depicted diagrammatically in a. Purified D89E (b) cross-reacts with an anti-MFG-E8 antibody and runs at the same molecular weight as recombinant wild-type MFG-E8. The BV-2 cells phagocytosed BioParticles in the pHrodo assay from Molecular Probes after $2 \mathrm{~h}$ in culture (c). This phagocytosis was increased with the addition of $100 \mathrm{ng} / \mathrm{ml}$ MFG-E8 and inhibited by treatment with $4 \mu \mathrm{g} / \mathrm{ml}$ dominant negative D89E. Cells treated with a $4 \mu \mathrm{g} / \mathrm{ml} \mathrm{BSA}$ control showed no difference from the untreated control. The data are the mean \pm SEM from five replicates per experiment of three separate experiments and are expressed as percent of untreated control wells. Significant difference is from control, ${ }^{* *} p<0.001$ 



Fig. 4 MFG-E8 increases and D89E decreases the phagocytosis of apoptotic neurons by microglia. SY5Y cells labeled with CellTracker green were exposed to $20 \mathrm{~s}$ of UV light, and $5 \mathrm{~h}$ later, CellTracker redlabeled BV-2 cells were cocultured with SY5Y cells for $1 \mathrm{~h}$. Slides were then coverslipped with VectaShield containing DAPI for imaging. At the time of coculture, cells were treated with vehicle (a), $100 \mathrm{ng} / \mathrm{ml}$ MFG-E8 (b and inset in d), or $4 \mu \mathrm{g} / \mathrm{ml}$ D89E (c). Images were analyzed for colocalization of red and green dye with Image-

engulfment of SY5Y cells (Fig. 4b,d). As in the pHrodo assay, the presence of $4 \mu \mathrm{g} / \mathrm{ml}$ D89E inhibited phagocytosis (Fig. 4c). In many cases in the MFG-E8-treated cells, green SY5Y cells appeared fragmented inside red BV-2 cells (Fig. 4d), and occasionally two nuclei resided in one BV-2 cell (data not shown). Quantification of the data (Fig. 4E) showed that MFG-E8 treatment resulted in a significant increase in colocalization compared to UV treatment alone, and treatment with the $\mathrm{D} 89 \mathrm{E}$ dominant negative protein resulted in a significant decrease in colocalization. These results support the idea that microglial phagocytosis is mediated through an MFG-E8-dependent mechanism.

\section{Tg2576 mice produce lower levels of brain MFG-E8}

Data generated in the BV-2 cell culture system suggest that MFG-E8 plays a similar role in the clearance of apoptotic neurons in the brain as it does in the clearance of apoptotic cells in the peripheral immune system. Defects in this mechanism have been linked to several autoimmune and inflammatory disorders in the peripheral immune system (Asano et al. 2004; Hanayama et al. 2004, 2006; Miksa et al.

Quant and results are expressed as percent colocalization, which is defined as the overlap area of red and green staining as compared to total area analyzed. The data (d) are the mean \pm SEM from three independent experiments consisting of six randomly selected fields analyzed per experiment. The scale bar is equal to $100 \mu \mathrm{m}$ for $\mathbf{a}-\mathbf{c}$ and $50 \mu \mathrm{m}$ for the inset in d. Significant difference is from vehicle-treated cells, $* * p<0.001 ; * p<0.05$

2006; Yamaguchi et al. 2008), so a reasonable hypothesis would be that MFG-E8 may play a role in neurological conditions as well. To begin to examine this idea, we screened the Tg2576 mouse model of AD (Hsiao et al. 1996) for changes in brain MFG-E8 production compared to agematched wild-type animals (Fig. 5). Whole brain homogenates from 2-, 6-, 12-, and 18-month mice were compared by Western blot analysis. Wild-type animals displayed an increase in MFG-E8 levels with age that became significant at 12 months. In contrast, $\mathrm{Tg} 2576$ animals showed much lower levels of MFG-E8 that increased a small but significant amount at 18 months, yet was still below wildtype levels.

\section{Discussion}

In this study, we report several key findings. First, in a cell culture model system of glial-neuronal interactions, apoptotic neuroblastoma cells induce an increase in MFG-E8 production by the BV-2 microglial cell line. Second, we demonstrate that MFG-E8 stimulates microglial phagocy- 
A WT

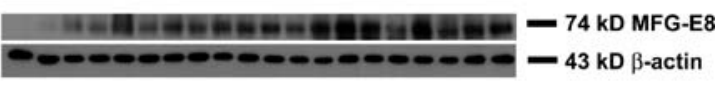

$\operatorname{Tg} 2576$



B

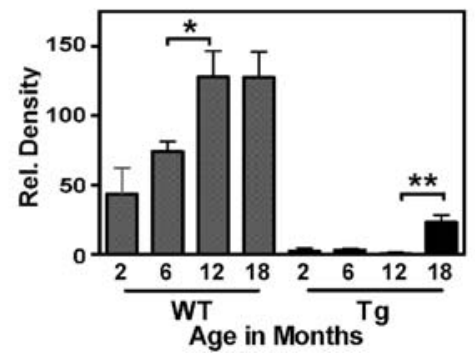

Fig. $5 \mathrm{Tg} 2576$ mice produce lower levels of brain MFG-E8 than wild-type mice. Whole brain homogenates from Tg2576 mice of various ages $(3,6,9,12,18$ months) and from wild-type age-matched littermates were probed for MFG-E8 levels by Western blot (a). Blots were quantified by densitometry and normalized to $\beta$-actin (b). Significant difference is shown, ${ }^{* *} p<0.001 ;{ }^{*} p<0.05$

tosis of both BioParticles and apoptotic neurons, and a dominant negative form of MFG-E8, which acts to mask the phosphatidylserine expressed on the apoptotic cell, blocks this phagocytic activity. We also show that treatment of BV-2 cells with the chemokine fractalkine (CXCL3) increases MFG-E8 protein production by these cells, suggesting a potential mechanism that drives the increase of phagocytosis of apoptotic SY5Y cells by BV-2 cells. Finally, when investigating a possible role for MFG-E8 in the progression of $\mathrm{AD}$, we discovered that brain MFG-E8 production is suppressed in the Tg2576 mouse model of AD. These data support a role for MFG-E8 in regulation of phagocytosis by microglia (see Fig. 6) and implicate this protein in the disease process of $\mathrm{AD}$.

Although the mechanism by which microglia recognize apoptotic cells in the brain has not been completely resolved, several important signals have been identified, such as the importance of PS expression, interaction with the vitronectin receptor on microglia, the CD36 scavenger receptor, TREM-2, and most recently Gas6 (Grommes et al. 2008; Stolzing and Grune 2004; Takahashi et al. 2005; Witting et al. 2000). Like MFG-E8, Gas6 binds to PS (Ishimoto et al. 2000) and links apoptotic cells to phagocytes. In the periphery, a link between Gas6 and MFG-E8 has been identified, referred to as the "tether and tickle" (Hoffmann et al. 2001). The "tether," recognition and binding of apoptotic cells to phagocytes, is often mediated by integrins, such as in MFG-E8 binding, and is not sufficient for engulfment. The "tickle" signals an internalization of bound particles and induction of downstream signaling cascades and functions through the receptor tyrosine kinase Mer (Scott et al. 2001; Todt et al. 2004). Taken together, strong adhesion through tethering with molecules like MFG-E8 in combination with the conversion of this binding to a signaling event through tickling molecules such as Gas6 create a multiple step model required for proper clearance of apoptotic cells. Likewise, Gas6 was shown to function in microglia to aid in phagocytosis via Rac activation and suppress inflammation as it does in the peripheral immune system (Grommes et al. 2008). However, while association of apoptotic cells and microglia was enhanced by the addition of Gas 6 in the study of Grommes et al., phagocytosis was not enhanced, indicating that the Gas6-Mer interaction is not sufficient for engulfment. Based on our findings in the current study, we suggest that Gas6 and MFG-E8 are fulfilling their roles in the brain of the tether-tickle scenario modeled in the periphery.

Treatment of microglia with the chemokine fractalkine was previously linked to MFG-E8 mRNA expression (Leonardi-Essmann et al. 2005), and we have extended these findings to MFG-E8 protein production and release by microglial cells. Fractalkine is known to be released from injured neurons, and the addition of fractalkine to microglia has been reported to induce chemotaxis resulting in a threefold increase in the number of glial cells, a response which is blocked by antifractalkine antibodies (Harrison et al. 1998). This recruitment of microglia to a site of neuronal injury coupled with the induction of MFGE8 by fractalkine led us to hypothesize that fractalkine stimulation of MFG-E8 played a role in enabling micro-



Fig. 6 Proposed model for MFG-E8-mediated phagocytosis of apoptotic neurons by microglia. Cell stress from normal aging, disease, or injury induces apoptosis in neurons, resulting in a redistribution of the plasma membrane and the exposure of PS on the cell surface. Microglia produce and release MFG-E8 to scan the environment for apoptotic cells. Once PS is detected, MFG-E8 binds to it, allowing it to bind back to an integrin receptor on the microglia thus acting as a tether. This association of the cells allows the microglia to develop into a phagocyte and engulf the apoptotic neuron, ultimately protecting the surrounding tissue from potentially harmful cellular debris 
glial-mediated phagocytosis of apoptotic neurons. The robust increase in MFG-E8 induced by coculturing an apoptotic neuronal cell line with a microglial cell line supports this theory and suggests that this protein may be involved in the recognition of apoptotic cells in the brain in a similar way as in the periphery.

Our data showing that MFG-E8 added to a BioParticle phagocytosis assay with $\mathrm{BV}-2$ cells leads to an increase in phagocytosis also support our hypothesis. Furthermore, the phagocytosis of apoptotic SY5Y cells by BV-2 cells is increased in the presence of MFG-E8, and the dominant negative form of MFG-E8 inhibits phagocytosis in both of these assays. In the peripheral immune system, macrophages cocultured with apoptotic cells show an increase of about $40 \%$ in the phagocytosis of PS-expressing cells when MFGE8 is added that is similar in scale to the roughly $27 \%$ increase in phagocytosis that we report here (Hanayama et al. 2002). The involvement of endogenous MFG-E8 produced by BV-2 cells may account for the high basal levels of phagocytosis that we see in this assay, and therefore the addition of recombinant MFG-E8 yields a modest stimulation of phagocytic activity. In addition, masking the PS with D89E, the dominant negative form of the protein, inhibits phagocytosis by about $60 \%$, the same magnitude of inhibition that we found in microglia (Hanayama et al. 2002). Altogether, these data support the hypothesis that MFG-E8 binds apoptotic neurons and enables their clearance by microglia. To provide further support for this hypothesis, future studies with primary microglia and neurons will be important. Also, because our results implicate fractalkine in stimulating MFG-E8 in microglia, the ability of fractalkine to stimulate phagocytosis of apoptotic neurons by microglia needs further examination.

There is evidence that MFG-E8 plays a role in the pathological process of several diseases. In sepsis, several cell types undergo apoptosis, and the inflammatory state induced by severe infection downregulates the production of MFG-E8. Interestingly, treatment with exosomes containing MFG-E8 increased the clearance of apoptotic cells, reduced levels of TNF- $\alpha$ and IL-6, and increased survival in a cecal ligation model of sepsis in rats (Miksa et al. 2006). MFG-E8 has also been proposed to be involved in intestinal mucosa repair, tumor growth, systemic lupus erythematosus, and AD (Boddaert et al. 2007; Bu et al. 2007; Fens et al. 2008; Wu et al. 2006; Yamaguchi et al. 2008). A recent report shows MFG-E8 mRNA expression was decreased in $\mathrm{AD}$ brains as compared to age-matched controls, and less MFG-E8 was found in areas of abundant plaques. In addition, the study suggested an MFG-E8dependent mechanism for phagocytosis of $\mathrm{A} \beta 1-42$ (Boddaert et al. 2007). Similarly, we found lower levels of MFG-E8 expression in the Tg2576 mouse model of $\mathrm{AD}$, a model which overexpresses the $\mathrm{APP}_{(\mathrm{swe})}$ mutation.
The finding of low levels of MFG-E8 protein in the Tg2576 mouse model of AD suggests that dysregulation of the protein is somehow involved in the pathological process of this disease. Previous research in this model shows that fractalkine is also inhibited in these mice at 9 months and returns to wild-type levels at 11 months (Duan et al. 2008). Likewise, we have shown that fractalkine is capable of regulating MFG-E8 production in microglial cells. However, the low levels of MFG-E8 protein detected in young $\mathrm{Tg} 2576$ mice suggests that something in this model is acting to suppress the protein product. In the peripheral immune system as well as in microglia, data show that LPS, a toll-like receptor agonist, inhibits MFG-E8 production by macrophages (Jinushi et al. 2007; Miyasaka et al. 2004). Young Tg2576 mice have high levels of soluble $\mathrm{A} \beta$, and cognitive deficits are seen in these mice before plaque deposition occurs (Lindner et al. 2006). It may be possible that soluble $\mathrm{A} \beta$ species, which have been shown to activate microglia, inhibit MFG-E8 production by a similar mechanism. As soluble $\mathrm{A} \beta$ accumulates into insoluble plaques in this animal model, a corresponding rise in MFG-E8 production is seen, suggesting a shift back toward normal MFG-E8 production or stimulation by apoptotic cells in the brain tissue.

In conclusion, the data reported here have implicated MFG-E8 in the clearance of apoptotic material in the brain by microglia. In addition, our finding that fractalkine stimulates MFG-E8 protein production, combined with published reports of altered fractalkine levels in diseases such as AD and HIV-1-associated dementia, indicates that MFG-E8 may play an important role in signaling microglia for phagocytosis following neural insults. This is also supported by our discovery of suppressed MFG-E8 levels in the brains of the Tg2576 mouse model of AD. Further work on the mechanism of MFG-E8 suppression in AD may uncover potential therapeutic strategies for the treatment of $\mathrm{AD}$ and other neurodegenerative diseases.

Acknowledgements The authors thank Dr. Shigekazu Nagata (Osaka University Medical School) for the D89E construct and Dr. Robert Vassar (Northwestern University) for the Tg2576 hemibrain homogenates.

Sources of support This work was supported in part by NIH grant R37 AG013939. AF was a predoctoral trainee on NIH T32 AG000260 and is currently supported by NIH F31 NS052043 predoctoral fellowship.

Open Access This article is distributed under the terms of the Creative Commons Attribution Noncommercial License which permits any noncommercial use, distribution, and reproduction in any medium, provided the original author(s) and source are credited. 


\section{References}

Akakura S, Singh S, Spataro M, Akakura R, Kim JI, Albert ML et al (2004) The opsonin MFG-E8 is a ligand for the alphavbeta5 integrin and triggers DOCK180-dependent Rac1 activation for the phagocytosis of apoptotic cells. Exp Cell Res 292:403-416 doi:10.1016/j.yexcr.2003.09.011

Albert ML, Kim JI, Birge RB (2000) alphavbeta5 integrin recruits the CrkII-Dock180-rac1 complex for phagocytosis of apoptotic cells. Nat Cell Biol 2:899-905 doi:10.1038/35046549

Asano K, Miwa M, Miwa K, Hanayama R, Nagase H, Nagata S et al (2004) Masking of phosphatidylserine inhibits apoptotic cell engulfment and induces autoantibody production in mice. J Exp Med 200:459-467 doi:10.1084/jem.20040342

Bazan JF, Bacon KB, Hardiman G, Wang W, Soo K, Rossi D et al (1997) A new class of membrane-bound chemokine with a CX3C motif. Nature 385:640-644 doi:10.1038/385640a0

Blasi E, Barluzzi R, Bocchini V, Mazzolla R, Bistoni F (1990) Immortalization of murine microglial cells by a v-raf $/ \mathrm{v}-\mathrm{myc}$ carrying retrovirus. J Neuroimmunol 27:229-237 doi:10.1016/ 0165-5728(90)90073-V

Boddaert J, Kinugawa K, Lambert JC, Boukhtouche F, Zoll J, Merval $\mathrm{R}$ et al (2007) Evidence of a role for lactadherin in Alzheimer's disease. Am J Pathol 170:921-929 doi:10.2353/ajpath.2007. 060664

Bu HF, Zuo XL, Wang X, Ensslin MA, Koti V, Hsueh W et al (2007) Milk fat globule-EGF factor 8/lactadherin plays a crucial role in maintenance and repair of murine intestinal epithelium. J Clin Invest 117:3673-3683

Chen J, Carey K, Godowski PJ (1997) Identification of Gas6 as a ligand for Mer, a neural cell adhesion molecule related receptor tyrosine kinase implicated in cellular transformation. Oncogene 14:2033-2039 doi:10.1038/sj.onc.1201039

Duan RS, Yang X, Chen ZG, Lu MO, Morris C, Winblad B et al (2008) Decreased fractalkine and increased IP-10 expression in aged brain of APP(swe) transgenic mice. Neurochem Res 33:1085-1089 doi:10.1007/s11064-007-9554-Z

Erichsen D, Lopez AL, Peng H, Niemann D, Williams C, Bauer M et al (2003) Neuronal injury regulates fractalkine: relevance for HIV-1 associated dementia. J Neuroimmunol 138:144-155 doi:10.1016/ S0165-5728(03)00117-6

Fadok VA, Bratton DL, Konowal A, Freed PW, Westcott JY, Henson PM (1998) Macrophages that have ingested apoptotic cells in vitro inhibit proinflammatory cytokine production through autocrine/paracrine mechanisms involving TGF-beta, PGE2, and PAF. J Clin Invest 101:890-898 doi:10.1172/JCI1112

Fadok VA, Bratton DL, Rose DM, Pearson A, Ezekewitz RA, Henson PM (2000) A receptor for phosphatidylserine-specific clearance of apoptotic cells. Nature 405:85-90 doi:10.1038/35011084

Fens MH, Mastrobattista E, de Graaff AM, Flesch FM, Ultee A, Rasmussen JT et al (2008) Angiogenic endothelium shows lactadherin-dependent phagocytosis of aged erythrocytes and apoptotic cells. Blood 111:4542-4550 doi:10.1182/blood-200706-094763

Garden GA, Moller T (2006) Microglia biology in health and disease. J Neuroimmune Pharmacol 1:127-137 doi:10.1007/s11481-006-9015-5

Grommes C, Lee CY, Wilkinson BL, Jiang Q, Koenigsknecht-Talboo JL, Varnum B et al (2008) Regulation of microglial phagocytosis and inflammatory gene expression by Gas6 acting on the axl/mer family of tyrosine kinases. J Neuroimmune Pharmacol 3:130 140 doi:10.1007/s11481-007-9090-2

Hall MO, Obin MS, Heeb MJ, Burgess BL, Abrams TA (2005) Both protein $\mathrm{S}$ and Gas6 stimulate outer segment phagocytosis by cultured rat retinal pigment epithelial cells. Exp Eye Res 81:581591 doi:10.1016/j.exer.2005.03.017
Hanayama R, Tanaka M, Miwa K, Shinohara A, Iwamatsu A, Nagata S (2002) Identification of a factor that links apoptotic cells to phagocytes. Nature 417:182-187 doi:10.1038/417182a

Hanayama R, Tanaka M, Miyasaka K, Aozasa K, Koike M, Uchiyama $Y$ et al (2004) Autoimmune disease and impaired uptake of apoptotic cells in MFG-E8-deficient mice. Science 304:11471150 doi:10.1126/science. 1094359

Hanayama R, Miyasaka K, Nakaya M, Nagata S (2006) MFG-E8dependent clearance of apoptotic cells, and autoimmunity caused by its failure. Curr Dir Autoimmun 9:162-172

Harrison JK, Jiang Y, Chen S, Xia Y, Maciejewski D, McNamara RK et al (1998) Role for neuronally derived fractalkine in mediating interactions between neurons and CX3CR1-expressing microglia. Proc Natl Acad Sci USA 95:10896-10901 doi:10.1073/ pnas.95.18.10896

Henson PM, Bratton DL, Fadok VA (2001) The phosphatidylserine receptor: a crucial molecular switch? Nat Rev Mol Cell Biol 2:627-633 doi:10.1038/35085094

Hoffmann PR, deCathelineau AM, Ogden CA, Leverrier Y, Bratton DL, Daleke DL et al (2001) Phosphatidylserine (PS) induces PS receptor-mediated macropinocytosis and promotes clearance of apoptotic cells. J Cell Biol 155:649-659 doi:10.1083/jcb.20010 8080

Hsiao K, Chapman P, Nilsen S, Eckman C, Harigaya Y, Younkin S et al (1996) Correlative memory deficits, Abeta elevation, and amyloid plaques in transgenic mice. Science 274:99-102 doi:10.1126/science.274.5284.99

Ishimoto Y, Ohashi K, Mizuno K, Nakano T (2000) Promotion of the uptake of PS liposomes and apoptotic cells by a product of growth arrest-specific gene, gas6. J Biochem 127:411-417

Jinushi M, Nakazaki Y, Dougan M, Carrasco DR, Mihm M, Dranoff G (2007) MFG-E8-mediated uptake of apoptotic cells by APCs links the pro- and antiinflammatory activities of GM-CSF. J Clin Invest 117:1902-1913 doi:10.1172/JCI30966

Kim TS, Lim HK, Lee JY, Kim DJ, Park S, Lee C et al (2008) Changes in the levels of plasma soluble fractalkine in patients with mild cognitive impairment and Alzheimer's disease. Neurosci Lett 436:196-200 doi:10.1016/j.neulet.2008.03.019

Leonardi-Essmann F, Emig M, Kitamura Y, Spanagel R, GebickeHaerter PJ (2005) Fractalkine-upregulated milk-fat globule EGF factor- 8 protein in cultured rat microglia. J Neuroimmunol 160:92-101 doi:10.1016/j.jneuroim.2004.11.012

Lindner MD, Hogan JB, Krause RG, Machet F, Bourin C, Hodges DB Jr et al (2006) Soluble Abeta and cognitive function in aged F344 rats and Tg2576 mice. Behav Brain Res 173:62-75 doi:10.1016/j.bbr.2006.06.003

Miksa M, Wu R, Dong W, Das P, Yang D, Wang P (2006) Dendritic cellderived exosomes containing milk fat globule epidermal growth factor-factor VIII attenuate proinflammatory responses in sepsis. Shock 25:586-593 doi:10.1097/01.shk.0000209533.22941.d0

Miksa M, Amin D, Wu R, Ravikumar TS, Wang P (2007) Fractalkineinduced MFG-E8 leads to enhanced apoptotic cell clearance by macrophages. Mol Med 13:553-560 doi:10.2119/2007-00019.Miksa

Miyasaka K, Hanayama R, Tanaka M, Nagata S (2004) Expression of milk fat globule epidermal growth factor 8 in immature dendritic cells for engulfment of apoptotic cells. Eur J Immunol 34:1414 1422 doi:10.1002/eji.200424930

Mochizuki H, Goto K, Mori H, Mizuno Y (1996) Histochemical detection of apoptosis in Parkinson's disease. J Neurol Sci 137:120-123 doi:10.1016/0022-510X(95)00336-Z

Oakley H, Cole SL, Logan S, Maus E, Shao P, Craft J et al (2006) Intraneuronal beta-amyloid aggregates, neurodegeneration, and neuron loss in transgenic mice with five familial Alzheimer's disease mutations: potential factors in amyloid plaque formation. J Neurosci 26:10129-10140 doi:10.1523/JNEUROSCI.120206.2006 
Petrova TV, Akama KT, Van Eldik LJ (1999) Cyclopentenone prostaglandins suppress activation of microglia: down-regulation of inducible nitric-oxide synthase by 15-deoxy-Delta12,14prostaglandin J2. Proc Natl Acad Sci USA 96:4668-4673 doi:10.1073/pnas.96.8.4668

Savill J, Fadok V (2000) Corpse clearance defines the meaning of cell death. Nature 407:784-788 doi:10.1038/35037722

Scott RS, McMahon EJ, Pop SM, Reap EA, Caricchio R, Cohen PL et al (2001) Phagocytosis and clearance of apoptotic cells is mediated by MER. Nature 411:207-211 doi:10.1038/35075603

Stolzing A, Grune T (2004) Neuronal apoptotic bodies: phagocytosis and degradation by primary microglial cells. FASEB J 18:743745

Su JH, Anderson AJ, Cummings BJ, Cotman CW (1994) Immunohistochemical evidence for apoptosis in Alzheimer's disease. Neuroreport 5:2529-2533

Takahashi K, Rochford CD, Neumann H (2005) Clearance of apoptotic neurons without inflammation by microglial triggering receptor expressed on myeloid cells-2. J Exp Med 201:647-657 doi:10.1084/jem.20041611

Thomas LB, Gates DJ, Richfield EK, O'Brien TF, Schweitzer JB, Steindler DA (1995) DNA end labeling (TUNEL) in Hunting- ton's disease and other neuropathological conditions. Exp Neurol 133:265-272 doi:10.1006/exnr.1995.1029

Todt JC, Hu B, Curtis JL (2004) The receptor tyrosine kinase MerTK activates phospholipase $\mathrm{C}$ gamma2 during recognition of apoptotic thymocytes by murine macrophages. J Leukoc Biol 75:705-713 doi:10.1189/jlb.0903439

Witting A, Muller P, Herrmann A, Kettenmann H, Nolte C (2000) Phagocytic clearance of apoptotic neurons by microglia/brain macrophages in vitro. Involvement of lectin-, integrin-, and phosphatidylserine-mediated recognition. J Neurochem 75:1060 1070 doi:10.1046/j.1471-4159.2000.0751060.x

Wu Y, Tibrewal N, Birge RB (2006) Phosphatidylserine recognition by phagocytes: a view to a kill. Trends Cell Biol 16:189-197 doi:10.1016/j.tcb.2006.02.003

Yamaguchi H, Takagi J, Miyamae T, Yokota S, Fujimoto T, Nakamura $S$ et al (2008) Milk fat globule EGF factor 8 in the serum of human patients of systemic lupus erythematosus. J Leukoc Biol 83:1300-1307 doi:10.1189/jlb.1107730

Zhang L, Kokkonen G, Roth GS (1995) Identification of neuronal programmed cell death in situ in the striatum of normal adult rat brain and its relationship to neuronal death during aging. Brain Res 677:177-179 doi:10.1016/0006-8993(95)00197-X 